\title{
Characterization of volatile composition of Laurencia dendroidea by gas chromatography- mass spectrometry
}

\author{
Vanessa Gressler, ${ }^{1}$ Mutue T. Fujii, ${ }^{2}$ Pio Colepicolo, ${ }^{1}$ Ernani \\ Pinto $^{*}, 1$ \\ ${ }^{1}$ Departamento de Análises Clínicas e Toxicológicas, Universidade de São \\ Paulo, Brazil, \\ ${ }^{2}$ Núcleo de Pesquisas em Ficologia, Instituto de Botânica, São Paulo, Brazil.
}

\begin{abstract}
In this study we report the characterization of the volatile compounds of Laurencia dendroidea. Solvent extracts (dichloromethane and methanol), hydrodistillation extracts and headspace solid-phase microextraction samples were obtained and analyzed by GC-MS. Forty-six volatile components were identified in $L$. dendroidea, among them hydrocarbons, alcohols, phenols, aldehydes, ketones, acids, esters and terpenes.
\end{abstract}

Revista Brasileira de Farmacognosia Brazilian Journal of Pharmacognosy 22(4): 805-812, Jul./Aug. 2012

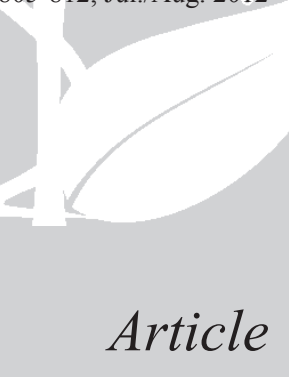

Received 10 Nov 2011

Accepted 2 Jan 2012

Available online 29 May 2012

Keywords:

Laurencia dentroidea hydrodistillation HS-SPME

solvent extracts volatile compounds GC-MS

ISSN 0102-695X http://dx.doi.org/10.1590/S0102695X2012005000069

\section{Introduction}

Red algae, especially many species of the genus Laurencia J.V. Lamouroux (Ceramiales, Rhodomelaceae), have proven to be a prolific source of secondary metabolites and have been the subject of intensive research in the field of marine natural products (Faulkner, 2000; Guaratini et al., 2005; Cardozo et al., 2006; Cardozo et al., 2007). Many of Laurencia's metabolites have been found to possess a variety of biological activities such as antibacterial (Vairappan, 2003; Kladi et al., 2008; Vairappan et al., 2008), cytotoxic (Kladi et al., 2006; Kladi et al., 2007; Cen-Pacheco et al., 2011; Lhullier et al., 2010), antioxidant (Li et al., 2009), antimalarial (Topcu et al., 2003), antihelmintic (Davyt et al., 2001), analgesic (Chatter et al., 2009), antitrypanossomal (Veiga-Santos et al., 2010) and antileishmanial (Machado et al., 2011) activities.

Volatile compounds play an important role in chemical communication for algae in marine ecosystems (Fink, 2007) and many of them also have other biological importance. These compounds can be obtained by several extraction processes like hydrodistillation (HD), hydrodestillation (HD) focused microwave-assisted hydrodistillation (FMA-HD), solvent extraction (SE), supercritical fluid extraction (SFE), headspace (HS) and headspace solid-phase microextraction (HS-SPME), and characterized by Gas Chromatography-Mass
Spectrometry (GC-MS) (Gressler et al., 2009).

Laurencia species are found all over the world in the tropical and subtropical seas. This genus comprises more or less 150 species and around thirty of them occur in Brazil (Machado et al., 2010). Therefore, the purpose of the present investigation was to identify the volatile compounds of $L$. dendroidea obtained by different extraction procedures (hydrodistillation, solvent extraction and by headspace solid-phase microextraction) using the GC-MS technique.

\section{Materials and Methods}

\section{Seaweed samples}

The red macroalgae Laurencia dendroidea (Mont) M. Howe was collected at Parati beach in Anchieta, Espírito Santo State, Brazil, in October 2006, and identified by Dr. Mutue Toyota Fujii. A voucher specimen was deposited in the São Paulo State Herbarium "Maria Eneyda P. K. Fidalgo" as SP 399.947.

\section{Hydrodistillation (HD)}

The hydrodistillation was done as previously described (Gressler et al., 2011). In summary, around $400 \mathrm{~g}$ of fresh material was extracted in a Clevenger-type apparatus for $4 \mathrm{~h}$. The essential oil was then diluted 100- 
fold with ethyl acetate prior to analysis by GC-MS.

\section{Solvent extraction (SE)}

The solvent extracts were obtained as follow: freeze-dried algae $(5 \mathrm{~g})$ were subjected to extraction with $50 \mathrm{~mL}$ of dichloromethane in an ultrasonic bath for 30 min. After that, the solvent was filtered through Whatman 41 filter paper. The remaining alga was re-extracted two more times and the combined solvent fractions concentrated by rotary evaporation. The algal residue was then extracted with $50 \mathrm{~mL}$ of methanol, also in an ultrasonic bath, for $30 \mathrm{~min}$. The solvent was filtered and the methanol extraction repeated 2 more times.

The residues of the dichloromethane extract (DE) and the methanol extract (ME) were resuspended in $1 \mathrm{~mL}$ of ethyl acetate and analyzed separately by GC-MS.

\section{Headspace Solid-phase microextraction (HS-SPME)}

Because of the high water content present in algae and the desire to avoid drop formation in the extraction flasks, the extraction of the volatile compounds by HSSPME were performed with lyophilized algal material.

The HS-SPME parameters, including algae sample weight, extraction temperature, equilibrium time and extraction time, were optimized. For this optimization, three of the parameters were kept invariant and the other parameter changed, as described by Guo et al. (2006). The final optimal conditions resulted in the following procedure: lyophilized algae $(50 \mathrm{mg})$ were placed in a $10 \mathrm{~mL}$ glass flask and the flask hermetically sealed. In parallel, a second flask with the same amount of sample was sealed with a thermometer and used as temperature controller for the headspace. Both flasks were placed on a magnetic stirrer with heater. The temperature of the headspace $\left(60^{\circ} \mathrm{C}\right)$ was equilibrated for $15 \mathrm{~min}$ and then the SPME fiber exposed to the headspace. The HS-SPME extraction was performed during $15 \mathrm{~min}$ and, immediately afterward, the fiber was inserted into the injector of the GC-MS for analysis. The fiber was left inside the injector during $10 \mathrm{~min}$ to assure that all compounds were desorbed. Four different types of adsorbents were used in order to extract different groups of analytes, these being: polydimethylsiloxane (PDMS), $100 \mu \mathrm{m}$; polydimethylsiloxane-divinylbenzene (PDMSDVB), $65 \mu \mathrm{m}$; carboxen-polydimethylsiloxane (CARPDMS), $75 \mu \mathrm{m}$; and polyacrylate (PA), $85 \mu \mathrm{m}$.

\section{Gas chromatography/mass spectrometry (GC-MS) analysis}

The samples of volatile compounds extracted by the different procedures were analyzed in a gas chromatograph coupled to a mass spectrometer (GCMS-
QP2010 Plus, Shimadzu, Japan). The chromatographic separation was achieved with an Rtx-5MS capillary column (30 m x $0.25 \mathrm{~mm} \times 0.1 \mu \mathrm{m})$ and helium was used as the carrier gas (with a flow rate of $1 \mathrm{~mL} \cdot \mathrm{min}^{-1}$ ). The oven temperature was increased at a rate of $3{ }^{\circ} \mathrm{C} \cdot \mathrm{min}^{-1}$ from 60 to $260{ }^{\circ} \mathrm{C}$ and held at the latter temperature for $40 \mathrm{~min}$. Injection and transfer line temperatures were 220 and $240{ }^{\circ} \mathrm{C}$. The detection was performed in the full scan mode, with a mass range of 50-650 $\mathrm{m} / \mathrm{z}$. Electron impact ionization was employed with a collision energy of $70 \mathrm{eV}$ and the mass spectrometer ion source was maintained at $240{ }^{\circ} \mathrm{C}$.

\section{Qualitative and quantitative analysis}

The volatile compounds were identified by matching mass spectra with spectra of reference compounds present in the National Institute of Standards and Technology (NIST 08) mass spectral library and by comparison with the literature Kovats Index (KI). When there was no spectrum for comparison, no identification was proposed. The relative amounts of individual components were expressed as percent peak areas relative to the total peak area.

\section{Antimicrobial and antioxidant tests}

The antimicrobial and antioxidant activities were done as previously described (Gressler et al., 2010; 2011).

For the antimicrobial test, the microorganisms used were: Staphylococcus aureus (ATCC 29213), Bacillus subtilis (ATCC 6633), Enterococcus faecalis (ATCC 29212), Streptococcus pneumoniae (ATCC 49619), Klebsiella pneumoniae (ATCC 13883), Salmonella typhi (ATCC 19430), Escherichia coli (ATCC 25922) and Pseudomonas aeruginosa (ATCC 27853), and one yeast strain, Candida albicans, (ATCC 10231). The Minimal Inhibitory Concentration (MIC) was determined according to NCCLS M100-S15 and M38-A (NCCLS, 1998 and 2005).

The 2,2-diphenyl-2-picrylhydrazyl (DPPH) antioxidant test was done according to Yen \& Chan (1995) with some modifications. The chemiluminescence antioxidant test was performed according to Krol et al. (1994).

\section{Results and Discussion}

\section{Optimization of HS-SPME extraction}

In order to identify the largest possible number of volatile compounds of the algae by HS-SPME, four different fibers, i.e., PDMS, PDMS-DVB, CAR-PDMS and PA, were chosen. The PDMS fiber is more suitable for the analysis of low molecular weight polar and non- 
polar compounds, PDMS-DVB for alcohols and amines, CAR-PDMS for hydrocarbons and PA for phenols and carboxylic acids.

To optimize the HS-SPME extraction conditions, the total peak area was used as a parameter. First, the amount of lyophilized algae was investigated. For this, the intermediate values of extraction temperature (60 $\left.{ }^{\circ} \mathrm{C}\right)$, equilibrium time $(15 \mathrm{~min})$ and extraction time (15 min) were selected. Analysis with 50, 100 and $200 \mathrm{mg}$ of lyophilized algae, showed a gradual increase of the total peak area with increasing amount of algae. However, when $50 \mathrm{mg}$ was used, the chromatograms obtained were cleaner, with less peak overlap and without loss of a number of peaks. This result was observed for all types of fibers tested, with the exception of the PA fiber and $L$. intricata, where $200 \mathrm{mg}$ of algae was used.

Having selected the amount of algae, different equilibrium and extraction times were evaluated $(5,15$ and $25 \mathrm{~min}$ each) at the extraction temperature of $60{ }^{\circ} \mathrm{C}$. The total peak area increased with the increase in the temperature used. Regarding the equilibrium time, no relevant differences were observed in the composition and relative amount of the extracted volatile compounds. On the other hand, the extraction time intervals showed a tendency toward fiber saturation, leading to broadening and overlapping of some of the peaks and a rise in the base line of the chromatograms. Thus, in order to reduce the extraction time and to obtain more informative chromatograms, equilibrium and extraction times of 15 min were chosen.

The use of a high sampling temperatures can induce degradation of volatiles. Therefore, the temperature range studied was restricted to $40-80{ }^{\circ} \mathrm{C}$. The extraction and equilibrium times were kept constant and the extraction carried out at 40,60 and $80{ }^{\circ} \mathrm{C}$. This resulted in expressive differences between the chromatograms. In general, at $40{ }^{\circ} \mathrm{C}$, some peaks disappeared and others decreased in intensity when compared with 60 and $80{ }^{\circ} \mathrm{C}$. Comparing the chromatograms at extraction temperatures of 60 and $80{ }^{\circ} \mathrm{C}$, the same number of peaks was observed. However, an increase in the peaks intensities, peak overlap and an increase of the chromatographic base line were seen when $80{ }^{\circ} \mathrm{C}$ was employed. Considering these factors, the extraction temperature that gave the best response was $60{ }^{\circ} \mathrm{C}$. According to Guo et al. (2006), the diffusion coefficients of the analytes increase with an increase in temperature and the concentration of the volatile components in the headspace should be increased, favoring extraction at higher temperatures. On the other hand, the partition coefficients of the analytes between the microdrop and the headspace decrease with increasing temperature and, consequently, decrease the amount extracted.

\section{Analysis of the volatile compounds}

The species $L$. dendroidea showed 203 different volatile compounds by the extraction methods performed, some of them being particular to one type of extraction and others common to two or more samples. It was possible to identify only 46 metabolites, probably because of the absence of algae-derived compounds in the GC-MS libraries. Among the compounds identified, terpenes, alcohols, acids, esters, ketones and hydrocarbons were found.

As previous reported by Gressler et al. (2011), the sesquiterpenes 7-epi-silphiperfolan-6 $\beta$-ol and silphiperfolan-7 $\beta$-ol have the same retention time and the identifications were done by the comparison of the mass spectral overlap obtained with laboratory standards of both compounds and by the individual KI. Table 1 shows the composition of $L$. dendroidea in more details.

\section{Antimicrobial and antioxidant activities}

The dichloromethane and methanol extracts were tested to verify their antimicrobial and antioxidant activities. No significant antimicrobial inhibition was observed for the microorganism at the concentrations tested.

The results summarized in Figure 1 show that both extracts were effective towards the scavenging of DPPH radicals. The dichloromethane extract showed a better antioxidant activity $\left(65.4 \pm 2.4 \%\right.$ at $\left.500 \mu \mathrm{g} \cdot \mathrm{mL}^{-1}\right)$ comparing to the methanol extract $\left(32.7 \pm 1.1 \%\right.$ at $\left.500 \mu \mathrm{g} \cdot \mathrm{mL}^{-1}\right)$ by the DPPH method and by the chemiluminescence method $\left(\sim 100 \%\right.$ at $500 \mu \mathrm{g} . \mathrm{mL}^{-1}$ for $\mathrm{DE}$ and $25.9 \pm 1.2 \%$ at 500 $\mu \mathrm{g} . \mathrm{mL}^{-1}$ for ME). For the DE, the IC50 obtained were $340.9 \mu \mathrm{g} \cdot \mathrm{mL}^{-1}$ by the DPPH method and $48.5 \mu \mathrm{g} \cdot \mathrm{mL}^{-1}$ by the chemiluminescence method. The antioxidant profile of both extracts by the two methods is shown in Figure 1. The antimicrobial and antioxidant activities of the essential oil of $L$. dendroidea have already been published (Gressler et al., 2011).

The DPPH radical scavenging assay has often been performed for evaluation of the anti-radical activity of antioxidants since DPPH possesses an odd electron, responsible for the strong absorption peak at $517 \mathrm{~nm}$ (Ayhan-Kilcigil et al., 2004). However, formation of free radical intermediates from oxidized compounds, which could become important propagators of free radical chain reactions, cannot be detected by this assay (Okawa et al., 2001). The chemiluminescence method, the other experimental model used, is based on the antioxidantdependent quenching of the chemiluminescence generated by luminol/peroxidase $/ \mathrm{H}_{2} \mathrm{O}_{2}$ (Dodeigene et al., 2000). According to Hirayama et al. (1997), the chemiluminescence method is more sensitive because of the high light emission. Those methods are often used as complementary assays in order to provide comparative results. 


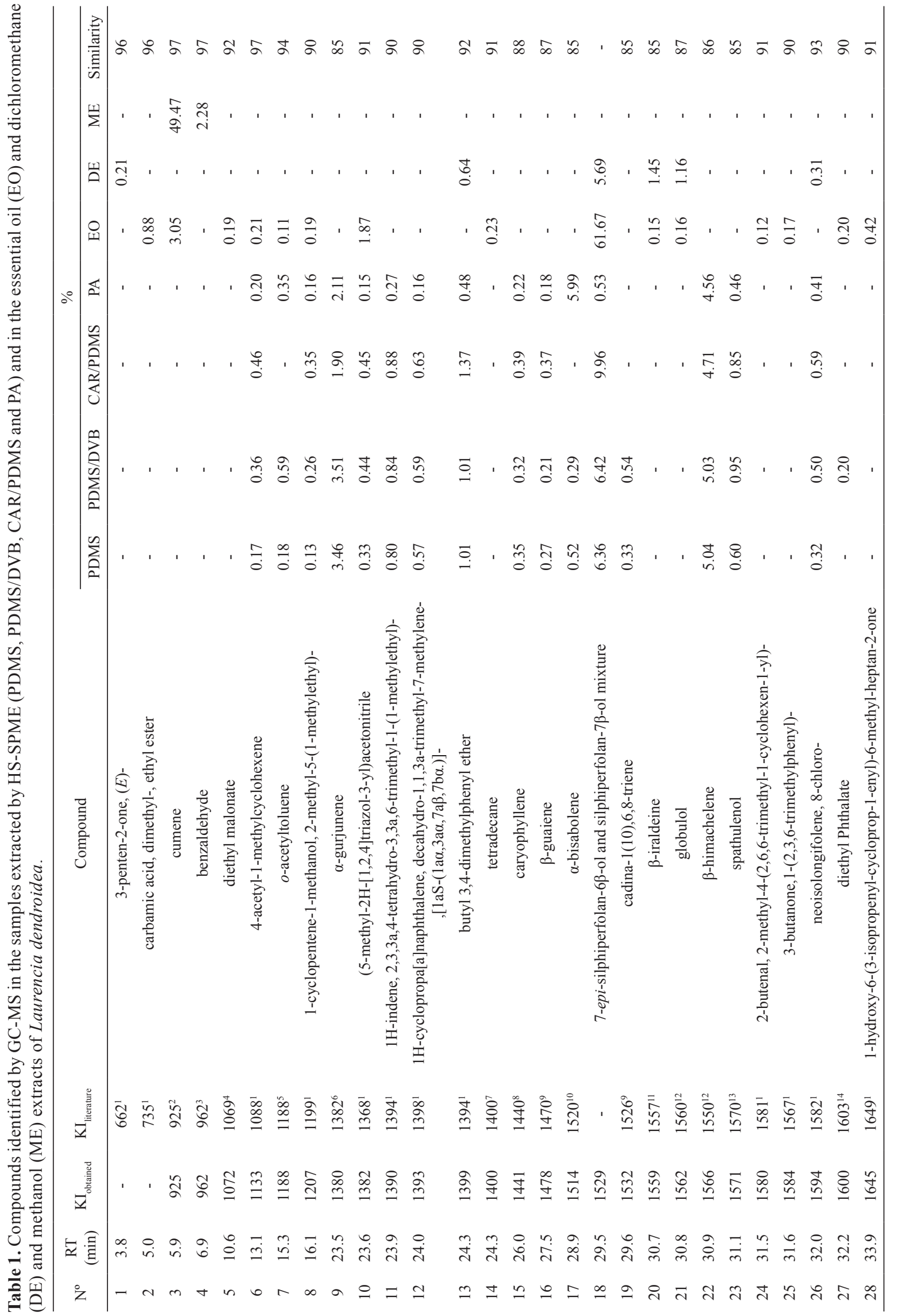




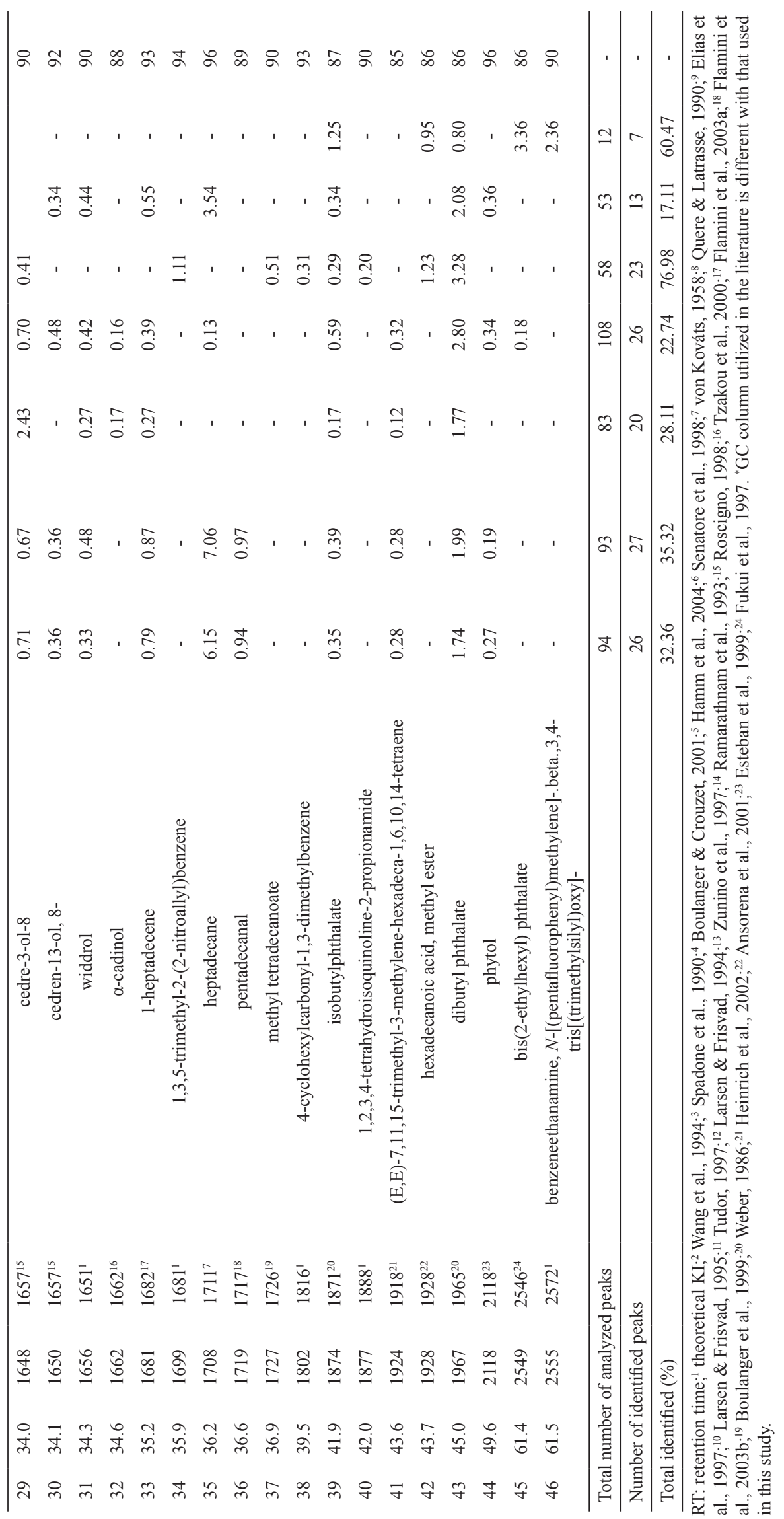


a)

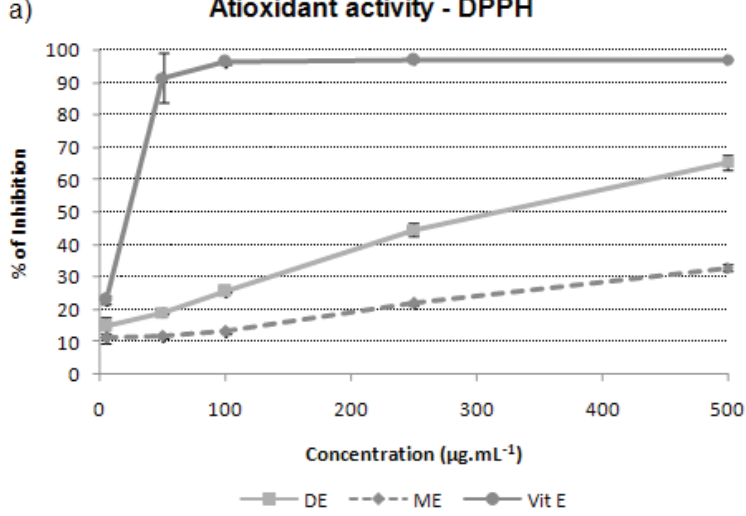

b) Antioxidant Activity - Chemiluminescence

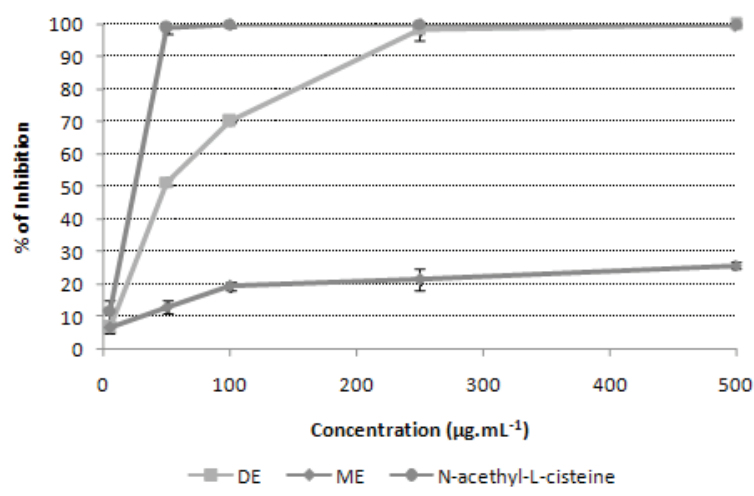

Figure 1. Comparative graphs of the antioxidant activity.

\section{Conclusions}

Volatile organic compounds obtained by different extraction procedures (hydrodistillation, solvent extraction and headspace solid-phase microextraction) provide complementary information of the organic compound profile, which is very important when an overview of the composition is required. In L. dendroidea, 46 volatile compounds were identified and the higher antioxidant activity of the dichloromethane extract indicates that the most active antioxidant components are in this fraction, although it is not possible to distinguish between the possibilities of the presence of just a few compounds with high potency or many constituents with low potencies. As indicated by this and previous reports, this species of algae could have many important applications and should be more thoroughly studied.

\section{Acknowledgments}

This work was supported by FAPESP, CAPES, CNPq, Ministério da Saúde, Ministério de Ciência e Tecnologia, NAP-USP de Biodiversidade Marinha and CNPq-INCT-Redoxoma.

\section{References}

Ansorena D, Gimeno O, Aatiasarán I, Bello J 2001. Analysis of volatile compounds by GC-MS of a dry fermented sausage: chorizo de Pamplona. Food Res Int 34: 67-75.

Ayhan-Kilcigil G, Kus C, Çoban T, Can-Eke B, Iscan M 2004. Synthesis and antioxidant properties of novel benzimidazole derivatives. $J$ Enzym Inhib Med Ch 19: 129-135.

Boulanger R, Chassagne D, Crouzet J 1999. Free and bound flavor components of amazonian fruits. 1: Bacuri. Flavour Frag J 14: 303-311.

Boulanger R, Crouzet J 2001. Identification of the aroma components of acerola (Malphigia glabra L.): free and bound flavor compounds. Food Chem 74: 209-216.

Cardozo KHM, Guaratini T, Barros MP, Falcão VR, Tonon AP, Lopes NP, Campos S, Torres MA, Souza AO, Colepicolo P, Pinto E 2007. Metabolites from algae with economical impact. Comp Biochem Phys C 146: 60-78.

Cardozo KHM, Carvalho VM, Pinto E, Colepicolo P 2006. Fragmentation of mycosporine-like amino acids by hydrogen/deuterium exchange and electrospray ionisation tandem mass spectrometry. Rapid Commum Mass Sp 20: 253-258.

Cen-Pacheco F, Villa-Pulgarin JA, Mollinedo F, Norte M, Daranas AH, Fernández JJ 2011. Cytotoxic oxasqualenoids from the red alga Laurencia viridis. Eur J Med Chem 46: 3302-3308.

Chatter R, Kladi M, Tarhouni S, Maatoug R, Kharrat R, Vagias C, Roussis V 2009. Neorogioltriol: A brominated diterpene with analgesic activity from Laurencia glandulifera. Phytochem Lett 2: 25-28.

Davyt D, Fernandez R, Suescun L, Mombru AW, Saldan J, Dominguez L, Coll J, Fujii MT, Manta E 2001. New sesquiterpene derivatives from the red alga Laurencia scoparia isolation, structure determination, and anthelmintic activity. J Nat Prod 64: 1552-1555.

Dodeigene C, Thunus L, Lejeune R 2000. Chemiluminescence as a diagnostic tool. A review. Talanta 51: 415-439.

Elias VO, Simoneit BRT, Cardoso JN 1997. Analysis of volatile sesquiterpenoids in environmental and geological samples. J High Res Chromatog 20: 305-309.

Esteban J, Martínez-Castro I, Vargas P, Sanz J 1999. Chemosystematic study on leaf volatile compounds of Saxifraga L. series Ceratophyllae (Saxifragaceae). Biochem Syst Ecol 27: 255-268.

Faulkner DJ 2000. Marine natural products. Nat Prod Rep 17: 7-55.

Fink P 2007. Ecological functions of volatile organic compounds in aquatic systems. Mar Freshw Behav Phy 40: 155168.

Flamini G, Cioni PL, Morelli I 2003a. Use of solid-phase microextraction as a sampling technique in the determination of volatiles emitted by flowers, isolated flower parts and pollen. J Chromatogr A 998: 229-233. 
Flamini G, Cioni PL, Morelli I, Ceccarini L, Andolfi L, Macchia M 2003b. Composition of the essential oil of Medicago marina L. from the coastal dunes of Tuscany, Italy. Flavour Frag J 18: 460-462.

Fukui H, Nagase M, Ono Y, Kawagoshi Y, Baba K, NOMA Y 1997. Determination of organic components in leachates from hazardous waste disposal sites in Japan by gas chromatography-mass spectrometry. $J$ Chromatogr A 774: 321-332.

Gressler V, Colepicolo P, Pinto E 2009. Useful Strategies for algal volatile analysis. Curr Anal Chem 5: 271-292.

Gressler V, Moura S, Flores AFC, Flores DC, Colepicolo P, Pinto E 2010. Antioxidant and antimicrobial properties of 2-(4,5-Dihydro-1H-pyrazol-1-yl)-pyrimidine and 1-carboxamidino-1H-pyrazole derivatives. J Brazil Chem Soc 21: 1477-1483.

Gressler V, Stein EM, Dörr F, Fujii MT, Colepicolo P, Pinto E 2011. Sesquiterpenes from the essential oil of Laurencia dendroidea (Ceramiales, Rhodophyta): isolation, biological activities and distribution among seaweeds. Rev Bras Farmacogn 21: 248-254.

Guaratini T, Vessecchi R, Pinto E, Colepicolo P, Lopes NP 2005. Balance of xanthophylls molecular and quasi-molecular ions in electrospray ionization. $J$ Mass Spectrom 40: 963-968.

Guo FQ, Huang LF, Zhou SY, Zhang TM, Liang YZ 2006. Comparison of the volatile compounds of Atractylodes nedicinal plants by headspace solidphase microextraction-gas chromatography-mass spectrometry. Anal Chim Acta 570: 73-78.

Hamm S, Bleton J, Tchapla A 2004. Headspace solid phase microextraction for screening for the presence of resins in egyptian archaeological samples. J Sep Sci 27: 235243.

Heinrich G, Pfeifhofer HW, Stabentheiner E, Sawidis T 2002. Glandular hairs of Sigesbeckia jorullensis Kunth (Asteraceae): morphology, histochemistry and composition of essential oil. Ann Bot 89: 459-469.

Hirayama O, Takagi M, Hukumoto K, Katoh S 1997. Evaluation of antioxidant activity by chemiluminescence. Anal Biochem 247: 237-241.

Kladi M, Vagias C, Stavri M, Rahman MM, Gibbons S, Roussis V 2008. C15 acetogenins with antistaphylococcal activity from the red alga Laurencia glandulifera. Phytochem Lett 1: 31-36.

Kladi M, Vagias C, Papazafiri P, Furnari G, Serio D, Roussis V 2007. New sesquiterpenes from the red alga Laurencia microcladia. Tetrahedron 63: 7606-7611.

Kladi M, Xenaki H, Vagias C, Papazafirib P, Roussis V 2006. New cytotoxic sesquiterpenes from the red algae Laurencia obtusa and Laurencia microcladia. Tetrahedron 62: 182-189.

Krol W, Czubaa Z, Schellara S, Paradowski Z, Shanitb J 1994. Structure-activity relationship in the ability of flavonols to inhibit chemiluminescence. J Ethnopharmacol 41:
121-126.

Larsen TO, Frisvad JC 1994. A simple method for collection of volatile metabolites from fungi based on diffusive sampling from Petri dishes. J Microbiol Meth 19: 297305.

Larsen TO, Frisvad JC 1995. Characterization of volatile metabolites from 47 Penicillium taxa. Mycol Res 99: 1153-1166.

Lhullier C, Falkenberg M, Ioannou E, Quesada A, Papazafiri P, Horta PA, Schenkel EP, Vagias C, Roussis V 2010. Cytotoxic halogenated metabolites from the brazilian red alga Laurencia catarinensis. J Nat Prod 73: 27-32.

Li YX, Li Y, Qian ZJ, Kim MM, Kim SK 2009. In vitro antioxidant activity of 5-HMF isolated from marine red alga Laurencia undulata in free radical mediated oxidative systems. J Microbiol Biotechn 19: 13191327.

Machado FL da S, Kaiser CR, Costa SS, Gestinari LM, Soares AR 2010. Atividade biológica de metabólitos secundários de algas marinhas do gênero Laurencia. Rev Bras Farmacogn 20: 441-452.

Machado FL da S, Pacienza-Lima W, Rossi-Bergmann B, Gestinari LM de S, Fujii MT, Paula JC de, Costa SS, Lopes NP, Kaiser CR, Soares AR 2011. Antileishmanial sesquiterpenes from the brazilian red alga Laurencia dendroidea. Planta Med 77: 733-735.

National Committee for Clinical Laboratory Standards 1998. Reference method for broth dilution antifungal susceptibility testing of conidium-forming filamentous fungi. Proposed standard M38-P. National Committee for Clinical Laboratory Standards, Wayne, PA, USA.

National Committee for Clinical Laboratory Standards 2005. Antimicrobial Susceptibility Testing. Proposed standard M100-S15. National Committee for Clinical Laboratory Standards, Wayne, PA, USA.

Okawa M, Kinjo J, Nohara T, Ono M 2001. DPPH (1,1diphenyl-2-picrylhydrazyl) radical scavenging activity of flavonoids obtained from some medicinal plants. Biol Pharm Bull 24: 1202-1205.

Quere JLL, Latrasse A 1990. Composition of the essential oils of Blackcurrant Buds (Ribes nigrum L.). J Agr Food Chem 38: 3-10.

Ramarathan N, Rubin LJ, Diosady LL 1993. Studies on meat flavor. 4. Fractionation, characterization, and quantitation of volatiles from uncured and cured beef and chicken. J Agr Food Chem 41: 939-945.

Roscigno G 1998. Estrazione supercritica di principi farmaceutici e biopesticidi.Salerno. 121p. Tese de Doutorado, Universita degli Studi di Salerno.

Senatore F, Soria EU, Soria RU, Porta GD, de Feo V 1998. Essential oil from two peruvian Satureja species. Flavour Frag J 13: 1-4.

Spadone JC, Takeoka G, Liardon R 1990. Analytical investigation of Rio off flavor in green coffee. $J \mathrm{Agr}$ Food Chem 38: 226-233. 
Topcu G, Aydogmus Z, Imre S, Goren AC, Pezzuto JM, Clement JA, Kingston DGI 2003. Brominated sesquiterpenes from the red alga Laurencia obtusa. J Nat Prod 66: 1505-1508.

Tudor E 1997. Temperature dependence of the retention index for perfumery compounds on a SE-30 glass capillary column. I. Linear equations. $J$ Chromatogr A 779: 287 297.

Tzakou O, Harvala C, Galati EM, Sanogo R 2000. Essential oil composition of Nepeta argolica Borey et Chaub. subsp. argolica. Flavour Frag J 15: 115-118.

Vairappan CS 2003. Potent antibacterial activity of halogenated metabolites from malaysian red algae, Laurencia majuscula (Rhodomelaceae, Ceramiales). Biomol Eng 20: 255-259.

Vairappan CS, Suzuki M, Ishii T, Okino T, Abe T, Masuda M 2008. Antibacterial activity of halogenated sesquiterpenes from Malaysian Laurencia spp. Phytochemistry 69: 2490-2494.

Veiga-SantosP,Pelizzaro-RochaKJ, SantosAO,Ueda-Nakamura T, Filho BPD, Suadatti, DB, Bianco EM, Pereira $\mathrm{RC}$, Nakamura CV 2010. In vitro antitrypanosomal activity of elatol isolated from red seaweed Laurencia dendroidea. Parasitology 137: 1661-70.

von Kováts E 1958. Gas-chromatographische charakterisierung organischer verbindungen. Teil 1: Retentionsindices aliphatischer halogenide, alkohole, aldehyde und ketone. Helv Chim Acta 41: 1915-1932.

Wang Z, Finglas M, Li K 1994. Fractionation of a light crude oil and identification and quantitation of aliphatic, aromatic, and biomarker comopunds by GC-FID and GC-MS, Part II. J Chromatogr Sci 32: 367-382.

Weber L 1986. Utilization of the Sadtler standard RI system in micropollution analyses. J High Res Chromatog 9: 446-451.

Yen GC, Chen HY 1995. Antioxidant activity of various tea extracts in relation to their antimutagenicity. $\mathrm{J} \mathrm{Agr} \mathrm{Food}$ Chem 43: 27-32.

Zunino MP, Novillo-Newton M, Maestri DM, Zygadlo JA 1997. Composition of the essential oil of Baccharis crispa Spreng. and Baccharis salicifolia Pers. grown in Cordoba (Argentina). Flavour Frag J 12: 405-407.

\section{*Correspondence}

Ernani Pinto

Departamento de Análises Clínicas e Toxicológicas, Faculdade de Ciências Farmacêuticas, Universidade de São Paulo

Av. Prof. Lineu Prestes, 580, Bloco 17, 05508-900 São PauloSP, Brazil

ernani@usp.br

Tel.: +55 1130911505

Fax: +55 1130919055 